\section{Production of Cuitlacoche [ Ustilago maydis (DS) Corda] on Sweet Corn}

\author{
J.K. Pataky \\ Department of Plant Pathology, University of Illinois, Urbana, IL 61801
}

Additional index words. common smut, huitlacoche, maize mushroom, Ustilago zeae, Zea mays

Abstract. In parts of central Mexico, galls of common smut, caused by Ustilago maydis ( Syn = Ustilago zeae Ung.), on ears of corn (Zea mays L.) are an edible delicacy known as cuitlacoche. Preliminary studies were done to identify methods to increase formation of ear galls on sweet corn. Of $\mathbf{3 7 0}$ sweet corn hybrids evaluated in disease nurseries, 38 hybrids were identified for which incidence of ear galls exceeded $40 \%$ in 1987 or 1988 or exceeded $12 \%$ in 1990 . Inoculation techniques for inducing ear galls were: 1) spraying sporidial suspensions between leaf sheaths and stalks at the sixth to eighth nodes; 2) injecting sporidial suspensions into the sixth to eighth internodes; 3) wounding leaf sheaths at the sixth to eighth nodes with sand, followed by spraying a sporidial suspension into wounds; and 4) wounding leaf sheaths at the sixth to eighth nodes with sand in which teliospores were mixed. Only the sporidial injection technique substantially increased the incidence of smut, but it increased the incidence of stalk, tassel, and leaf galls more than ear galls. Thus, additional research is needed to determine when and how to inoculate with $\boldsymbol{U}$. maydis to induce the formation of ear galls necessary to commercially produce cuitlacoche and to screen for disease resistance.

Common smut, caused by U. maydis, is a devastating disease of sweet corn; but in parts of central Mexico, smut galls on ears of corn (Fig. 1) are an edible delicacy known as cuitlacoche, i.e., huitlacoche (Kennedy, 1989). In Mexico, cuitlacoche is sold either fresh or canned. Recently, cuitlacoche has been marketed in urban areas of the United States as "maize mushrooms" or "Mexican truffles." Descriptions of this new, unusual food have appeared in the past 2 years in diverse popular periodicals.

Concurrent with the culinary interest in cuitlacoche, the potential of common smut as a cash crop has been noted in several popular agricultural publications. The current potential market for fresh cuitlacoche in the United States is estimated to be $>45,000 \mathrm{~kg}$ annually (Farm Journal, 1990). Fresh corn smut cannot be imported from Mexico. Therefore, buyers have paid growers in the United States as much as \$0.50/ear for sweet corn with large ear galls. Nevertheless, one firm was able to obtain only $1400 \mathrm{~kg}$ of ears of cuitlacoche from growers in the eastern United States in 1989.

Reports of cuitlacoche as a cash crop gen-

Received for publication 2 Nov. 1990. The cost of publishing this paper was defrayed in part by the payment of page charges. Under postal regulations, this paper therefore must be hereby marked advertisement solely to indicate this fact. erally have focused on gleaning infected ears from fields that are planted for normal production of sweet corn, but they have not considered the production of cuitlacoche as an alternative crop. To produce cuitlacoche commercially, techniques must be identified that consistently will induce the formation of ear galls. This paper reports on preliminary studies to identify methods to increase formation of ear galls on sweet corn.

Identification of susceptible hosts. Sweet corn hybrids differ in their resistance and susceptibility to $U$. maydis. A total of 370 commercial sweet corn hybrids were evaluated in Urbana, Ill., for the percent incidence of ear galls resulting from natural infection by $U$. maydis (Pataky and Headrick, 1988; Pataky et al., 1987, 1990); 150, 150, and 200 hybrids were evaluated in 1987, 1988, and 1990, respectively. Ninety hybrids were included in at least two of the three trials. The hybrids differed in maturity from $\sim 55$ to 90 days.

Hybrids were arranged in a randomized complete-block (RCB) design. Each experimental unit consisted of a single row that was $3.6 \mathrm{~m}$ long with $\approx 15$ plants per row. Rows of hybrids were replicated 15 times in 1987 and 18 times in 1988 and 1990. Trials were planted 15 May 1987, 17 May 1988, and 1 May 1990. Incidence of smut resulting from natural infection was assessed during the first week of August.
Incidence of ear galls ranged from $0 \%$ to $80 \%, 0 \%$ to $58 \%$, and $0 \%$ to $34 \%$, and grand means were $17.6 \%, 12.5 \%$, and $3.8 \%$ in 1987, 1988, and 1990, respectively. Incidence was $<10 \%$ for more than half of the hybrids evaluated in each trial, i.e., medians were $<10 \%$ (Table 1). Hybrids with an incidence of smut $>40 \%$ in 1987 or 1988 or $>12 \%$ in 1990 were considered susceptible because they were more than one SD above the grand mean, i.e., z-scores were $>1$.

Hybrids for which incidence of ear galls was low were not necessarily resistant to $U$. maydis because formation of ear galls depends on the growth stage at which plants are infected (Thakur et al., 1989). For example, in a different trial in Urbana, the smutsusceptible sweet corn hybrid 'Candy Bar' was planted in adjacent plots on 17 and 29 May 1988. Incidence of ear and stalk galls for the 17 May planting was $41 \%$ and $9 \%$, respectively, but incidence of ear and stalk galls for the 29 May planting was $0 \%$ and $24 \%$, respectively. Thus, ear galls did not develop on the susceptible hybrid planted 29 May, probably because meristematic tissues in the ear shoot were not infected.

Although the sweet corn hybrids identified in Table 1 are relatively susceptible to $U$. maydis compared with other sweet corn hybrids that are available commercially, other

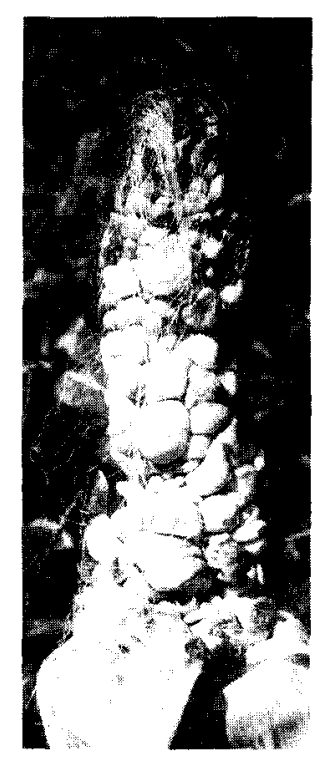

Fig. 1. Galls of common smut, Ustilago maydis, on ears of corn are considered an edible delicacy known as cuitlacoche in Mexico. Galls are at the most desirable stage for cuitlacoche $\approx 12$ to 16 days after midsilk. 
Table 1. Incidence (\%) of ear galls of Ustilago maydis on sweet corn hybrids identified as susceptible' to U. maydis, based on natural infection in field trials at Urbana, Ill., in 1987, 1988, and 1990.

\begin{tabular}{|c|c|c|c|c|c|}
\hline \multicolumn{2}{|l|}{1987} & \multicolumn{2}{|l|}{1988} & \multicolumn{2}{|l|}{1990} \\
\hline Hybrid & $\begin{array}{c}\text { Ear galls } \\
(\%)\end{array}$ & Hybrid & $\begin{array}{c}\text { Ear galls } \\
(\%)\end{array}$ & Hybrid & $\begin{array}{c}\text { Ear galls } \\
(\%)\end{array}$ \\
\hline XPH 2628 & 80 & Earlivee & 58 & Earlivee II & 34 \\
\hline Sch 4428 & 78 & Yankee Belle & 58 & Sch 4005 & 28 \\
\hline Crisp n Sweet 620 & 73 & SsuperSweet 7210 & 53 & HMX $8386 \mathrm{~S}$ & 22 \\
\hline $\operatorname{Sch} 4020$ & 73 & Spartan & 52 & SsuperSweet 7410 & 18 \\
\hline Crisp n Sweet 690 & 72 & FMX 271 & 51 & Spartan & 17 \\
\hline $\operatorname{Sch} 4016$ & 63 & Sch 4020 & 50 & Sweetie Biocolor 76 & 17 \\
\hline Sch 4009 & 59 & Sweet Dreams & 45 & Sch 7673 & 15 \\
\hline Yankee Belle & 52 & Silver Bullet & 42 & FMX 318 & 15 \\
\hline Sch 4026 & 51 & Candy Bar II & 41 & Sch 4040 & 14 \\
\hline Sch 5170 & 48 & Snowbelle & 41 & SsuperSweet $7801 \mathrm{~W}$ & 14 \\
\hline Swectic 70 & 47 & & & How Sweet It Is & 13 \\
\hline FMX 165 & 46 & & & Sch 5480 & 13 \\
\hline Sweetie Bicolor 76 & 46 & & & FMX 320 & 13 \\
\hline SsuperSweet 7602 & 45 & & & Sweetie 70 & 12 \\
\hline Paragon & 44 & & & XPH 3030 W Sh2 & 12 \\
\hline FMX 235 & 40 & & & Candy Bar II & 12 \\
\hline Sugar Buns & 40 & & & SsuperSweet 7702 BC & 12 \\
\hline Mean $(n=150)$ & 17.6 & Mean $(n=150)$ & 12.5 & $\operatorname{Mean}(n=200)$ & 3.8 \\
\hline Median & 9.3 & Median & 8.1 & Median & 1.8 \\
\hline Mode & $1-2$ & Mode & 0 & Mode & 0 \\
\hline
\end{tabular}

'Hybrids identified as susceptible had an incidence of ear galls that was at least one SD above the sample mean.

Table 2. Incidence $(\%)$ of $U$. maydis on sweet corn planted on four dates and inoculated with sporidia on 11 July 1989 by a leaf sheath spray or a stalk injection procedure.

\begin{tabular}{|c|c|c|c|c|c|c|c|c|c|c|}
\hline \multirow{4}{*}{$\begin{array}{l}\text { Application } \\
\text { method }\end{array}$} & \multicolumn{5}{|c|}{ Ear galls (\%) } & \multicolumn{5}{|c|}{ Plants with galls ${ }^{2}(\%)$} \\
\hline & \multicolumn{4}{|c|}{ Planting date } & & \multicolumn{4}{|c|}{ Planting date } & \multirow[b]{3}{*}{ Mean } \\
\hline & \multicolumn{2}{|c|}{ May } & \multicolumn{2}{|c|}{ June } & \multirow[b]{2}{*}{ Mean } & \multicolumn{2}{|c|}{ May } & \multicolumn{2}{|c|}{ June } & \\
\hline & 18 & 30 & 9 & 19 & & 18 & 30 & 9 & 19 & \\
\hline Controly & $<1$ & 0 & 0 & 0 & $<1$ & 2 & $<1$ & $\overline{0}$ & 0 & $<1$ \\
\hline Leaf sheath sprayx & 1 & $<1$ & 0 & 0 & $<1$ & 3 & 3 & 5 & 13 & 6 \\
\hline Stalk injection" & 8 & 7 & 1 & 0 & 4 & 19 & 45 & 67 & 68 & 49 \\
\hline Mean (planting date) & 3 & 2 & $<1$ & 0 & & 8 & 16 & 25 & 27 & \\
\hline
\end{tabular}

${ }^{2}$ Incidence of stalk, tassel, and/or leaf galls,

${ }^{y}$ Control = no inoculation.

${ }^{x}$ Leaf sheath spray $=$ sporidial suspension sprayed at $5.5 \times 10^{5} \mathrm{~Pa}$ with a hand-held gun into leaf sheaths at the sixth, seventh, and eighth nodes.

"Stalk injection $=2 \mathrm{ml}$ of a sporidial suspension injected with a modified Vaco Pistol Grip Syringe into stalks at the sixth, seventh, and eighth internodes.

germplasm may be more suitable for the production of cuitlacoche. Most sweet corn breeders discard genotypes or do not release experimental hybrids that are extremely susceptible to $U$. maydis. If available, these extremely susceptible genotypes would be ideal for production of cuitlacoche. Similarly, extremely susceptible genotypes may exist among dent, flint, floury, and other types of corn. Ear galls from these types of corn may be equally well suited for cuitlacoche, although buyers prefer ear galls from sweet corn. Bojanowski (1969) identified a susceptible flint corn inbred, U12, for which incidence of smut from natural infection was $100 \%$ in most seasons in Poland. Also, several investigators have observed that for some corn genotypes, gall formation is specific for certain tissues, such as ears, tassels, or nodal shoots (Christensen, 1963). Genotypes susceptible to gall formation on ears would be well suited for cuitlacoche.

Inoculation procedures and time of inoculation. Although the pathogenesis of $U$. maydis on corn is well studied (Christensen, 1963), the epidemiology of common smut is not understood completely. Davis (1936) noted that ear infections were prevalent in some years and rare in others, varying considerably in neighboring fields and in different sections of the same field. Investigations of environmental factors favoring smut infection have resulted in lists of variables that are contradictory (Smith and White, 1988). Meristematic tissue of above-ground plant parts can be infected. Galls may form on stalks, axillary buds, ears, leaves, and tassels. Infection occurs from sporidia that have been wind-disseminated or produced by germinating teliospores. Either teliospores or sporidia must be deposited in suitable infection sites on the host to induce infection. An early report indicated that systemic infection was rare, and that injury to plants was conducive to infection (Piemeisel, 1917). Higher incidence of smut at low plant populations also was reported (Wilcoxson, 1975).

Various inoculation methods to induce galls have been attempted to screen for smut resistance. Reviewing inoculation techniques evaluated in the early part of the century, Walter (1935) concluded that injury to young, rapidly growing plants increased severity of smut, but application of large amounts of inoculum in water did not. Likewise, Christensen (1963) noted there was no real evidence that spraying or dusting plants or seed with inoculum increased the incidence of infection; whereas injection of sporidial suspensions into leaf whorls resulted in a high incidence of plants with galls. Similarly, recent trials in Australia indicated that incidence of boil smut (i.e., common smut) on plants inoculated in the whorl was only $1.4 \%$ higher than on noninoculated plants (Nuberg et al., 1986). Conversely, Thakur et al. (1989) reported $100 \%$ incidence of tassel galls resulting from sporidial injection techniques, and $\approx 50 \%$ incidence of ear galls in greenhouse trials. Incidence of galls was related to the growth stage of the host at inoculation. Ear galls were induced at a high frequency when the sporidial suspension was injected between the leaf sheath and stalk at the sixth, seventh, and eighth nodes (the nodes at which ears were most likely to form) 0 to 8 days before tassel formation.

In 1989 and 1990, various inoculation procedures were evaluated in field trials in Urbana to identify methods that consistently induced formation of ear galls but were not as labor-intensive as the sporidial injection techniques of Christensen (1963) and Thakur et al. (1989). Such techniques would be useful for the commercial production of cuitlacoche and for screening germplasm in breeding programs for resistance to $U$. maydis.

In 1989 , the treatment design was $14 \times$ $4 \times 3$ factorial of hybrids, planting dates, and inoculation procedures. There were three replications arranged in a split-split plot of a RCB with 15 to 22 plants per experimental unit. Twelve susceptible and two relatively resistant hybrids were main plots. Subplots were four planting dates: 18 and 30 May and 9 and 19 June. Three inoculation procedures were applied on 1 July to sub-subplots. Inoculum was produced, and inoculation procedures were slightly modified from methods described previously (Thakur et al., 1989). Plants inoculated by the leaf sheath spray procedure were sprayed with a suspension of sporidia using a Spraymiser pistol-grip handheld spray gun (FMC Corp., Jonesboro, Ark.) operated at $\approx 5.5 \times 10^{5} \mathrm{~Pa}$. Sprays were directed at leaf sheaths from the sixth to eighth nodes. Plants inoculated by the stalk injection procedure were injected with $\sim 2 \mathrm{ml}$ of the sporidial suspension in the sixth or eighth internodes using a modified $50 \mathrm{ml}$ Vaco Pistol Grip Rubber Plunger Syringe (Ideal Instruments, Chicago). Plants in the control treatment were not inoculated.

Data were arcsin transformed to make variance more homogeneous before analysis of variance (ANOVA). The ANOVA for incidence of ear galls and galls on other plant tissues indicated significant differences among inoculation treatments and planting dates and an inoculation treatment $\times$ planting date interaction. Fewer than $1 \%$ of plants in the control treatment had galls (Table 2). Incidence of ear galls from the leaf sheath spray 


\begin{tabular}{|c|c|c|c|c|c|c|c|c|c|c|}
\hline \multirow[b]{4}{*}{ Hybridx } & \multicolumn{5}{|c|}{ Ear galls (\%) } & \multicolumn{5}{|c|}{ Plants with galls $(\%)$} \\
\hline & \multicolumn{4}{|c|}{ Planting date } & & \multicolumn{4}{|c|}{ Planting date } & \multirow[b]{3}{*}{ Mean } \\
\hline & \multicolumn{2}{|c|}{ May } & \multicolumn{2}{|c|}{ June } & \multirow[b]{2}{*}{ Mean } & \multicolumn{2}{|c|}{ May } & \multicolumn{2}{|c|}{ June } & \\
\hline & 18 & 30 & 9 & 19 & & 18 & 30 & 9 & 19 & \\
\hline Earlivee & $5^{w}$ & $0^{\mathrm{w}}$ & $8^{v}$ & 0 & 2 & $22^{w}$ & $13^{\mathrm{w}}$ & $84^{v}$ & 100 & 53 \\
\hline Spartan & $13^{w}$ & $10^{\mathrm{w}}$ & 0 & 0 & 7 & $43^{\mathrm{w}}$ & $13^{w}$ & 42 & 100 & 52 \\
\hline Sch 5170 & $7^{\mathrm{w}}$ & $14^{v}$ & 0 & 0 & 9 & $7^{\mathrm{w}}$ & $31^{v}$ & 100 & 100 & 64 \\
\hline Sweetie 70 & $13^{w}$ & $13^{\mathrm{v}}$ & 0 & 0 & 6 & $12^{\mathrm{w}}$ & $31^{\mathrm{v}}$ & 100 & 100 & 58 \\
\hline XPH 2623s & $8^{w}$ & $6^{v}$ & 0 & 0 & 4 & $17^{w}$ & $28^{v}$ & 86 & 83 & 45 \\
\hline Sch 4009 & $0^{\mathrm{w}}$ & $13^{v}$ & 0 & 0 & 4 & 0w & $38^{v}$ & 100 & 100 & 54 \\
\hline Sweetie Bicolor 76 & $13^{w}$ & $0^{2}$ & 0 & 0 & 3 & $13^{\mathrm{w}}$ & $46^{\mathrm{v}}$ & 100 & 80 & 57 \\
\hline Yankee Belle & $20^{\mathrm{w}}$ & $7 \mathrm{v}$ & 0 & 0 & 6 & $20^{\mathrm{w}}$ & $50^{\mathrm{v}}$ & 75 & 33 & 42 \\
\hline Candy Bar II & $13^{w}$ & $5^{v}$ & 0 & 0 & 4 & $13^{w}$ & $20^{2}$ & 75 & 50 & 36 \\
\hline FMX 271 & $7^{2}$ & $0^{\mathrm{w}}$ & 0 & 0 & 2 & $29^{\mathrm{v}}$ & $40^{2}$ & 83 & 85 & 54 \\
\hline SsuperSweet 7210 & $0^{2}$ & $0^{2}$ & 0 & 0 & 0 & $6^{v}$ & $36^{v}$ & 71 & 75 & 42 \\
\hline Platinum Lady & $3^{\mathbf{v}}$ & $0^{v}$ & 0 & 0 & 1 & $15^{\mathrm{v}}$ & $100^{\mathrm{v}}$ & 83 & 67 & 62 \\
\hline Miracle & $11^{v}$ & $9^{v}$ & 10 & 0 & 7 & $16^{\mathrm{v}}$ & $27^{2}$ & 60 & 33 & 29 \\
\hline Florida Staysweet & $0^{v}$ & 10 & 0 & 0 & 4 & $33^{v}$ & 100 & 0 & 0 & 41 \\
\hline Mean (planting date) & 8 & 6 & 1 & 0 & & 18 & 41 & 76 & 72 & \\
\hline $\operatorname{BLSD}^{\mathrm{u}}(\mathrm{k}=100)$ & \multicolumn{5}{|c|}{4.2} & \multicolumn{4}{|c|}{15.3} & \\
\hline
\end{tabular}

${ }^{2}$ Two milliliters of a sporidial suspension injected with a modified hog vaccinator into the sixth, seventh, or eighth internodes (or at the most recently formed internode for younger- plants).

'Incidence of stalk, tassel, and leaf galls.

xHybrids listed according to maturity in Urbana, Ill., in 1989.

"Silks and tassels emerged by 11 July.

"Tassels emerged by 11 July.

"BLSD $=$ Wallen-Duncan Bayesian LSD test, $P=0.05$.

Table 4. Incidence (\%) of ear galls 21 days after midsilk on three sweet corn hybrids wounded by sandblasting at the early or full-tassel growth stages in 1990 and inoculated with a sporidial suspension or teliospores of Ustilago maydis.

\begin{tabular}{|c|c|c|c|c|c|c|}
\hline \multirow[b]{3}{*}{ Hybrids } & \multicolumn{6}{|c|}{ Incidence of (\%) of ear galls } \\
\hline & \multirow[b]{2}{*}{ Control } & \multicolumn{2}{|c|}{ Early tassel stage } & \multicolumn{2}{|c|}{ Full-tassel stage } & \multirow{2}{*}{$\begin{array}{c}\text { Mean } \\
\text { (hybrid) }\end{array}$} \\
\hline & & Sporidia & Teliospores & Sporidia & Teliospores & \\
\hline $\begin{array}{l}\text { Snowbelle } \\
\text { SsuperSweet } 8701 \\
\text { Supersweet Jubilee } \\
\text { Mean (treatment) }\end{array}$ & $\begin{array}{l}24 \\
24 \\
13 \\
20\end{array}$ & $\begin{array}{l}30 \\
29 \\
17 \\
25\end{array}$ & $\begin{array}{l}29 \\
33 \\
22 \\
28\end{array}$ & $\begin{array}{l}26 \\
30 \\
24 \\
27\end{array}$ & $\begin{array}{l}28 \\
29 \\
15 \\
24\end{array}$ & $\begin{array}{l}27 \mathrm{~b} \\
29 \mathrm{~b} \\
18 \mathrm{a}\end{array}$ \\
\hline
\end{tabular}

${ }^{2}$ Hybrid means followed by different letters are significantly different according to the Wailer-Duncan Bayesian LSD test $(\mathrm{k}=100), P=0.05$.

and stalk injection procedures was only $0.4 \%$ and $4 \%$, respectively, but incidence of plants with galls was $6 \%$ and $49 \%$, respectively (Table 2). Planting date, which affected the growth stage of plants, affected host tissues on which galls formed from stalk injections (Table 3). Ear galls were more common for the two plantings in May than for the two plantings in June. Except on the hybrids 'Miracle' and 'Florida Staysweet', ear galls formed only on plants with tassels formed or forming at inoculation (Table 3). However, incidence of galls on other plant tissues resulting from the stalk injection procedure was $\sim 70 \%$ for plants on which tassels had not formed (Table 3).

In 1990, the treatment design was a $3 \mathrm{x}$ 5 factorial of hybrids and inoculation treatments. There were four replications arranged in a split-plot of a RCB design. Each experimental unit consisted of 12 rows, $3 \mathrm{~m}$ long, with 12 to 15 plants per row. The five inoculation treatments were applied to main plots. Three hybrids, 'Snowbelle', 'SsuperSweet 8701', and 'Supersweet Jubilee', were planted in the 12-row subplots on 1 May. One of the five inoculation treatments was a noninoculated control. The other four inoculation treatments were a $2 \times 2$ factorial consisting of two times of inoculation and two types of inoculum. Plants were inoculated as tassels began to emerge (6 July) or at the full tassel stage (13 July) with a sporidial suspension or with teliospores. The leaf sheaths from the sixth to eighth nodes of all plants were wounded immediately before inoculation. To wound plants, sand was discharged from a Sear's Heavy Duty Sandblasting System Model no. 916808 (Sears Roebuck, Chicago) operated at $4.1 \times 10^{5}$ $\mathrm{Pa}$. For one method of inoculation, a sporidial suspension was prepared as described by Thakur et al. (1989) and sprayed directly into the wounds created by sandblasting. For the other inoculation method, teliospores were obtained from galls collected in the greenhouse, dried, and thoroughly mixed with sand before the wounding procedure. Incidence of ear galls was assessed 13 Aug. Arcsin transformation of percentage data did not result in variances that were more homogeneous than nontransformed data; therefore, analyses were done on nontransformed data.

The ANOVA for incidence of ear galls indicated significant differences among hybrids, but inoculation techniques and the in- oculation by hybrid interaction were not significant. Incidence of ear galls was higher for 'Snowbelle' and 'SsuperSweet 8701' than for 'Supersweet Jubilee' (Table 4). Mean incidence of ear galls was $5 \%$ to $8 \%$ higher for inoculated treatments than the noninoculated treatment, but this difference was not significant as there was considerable variation among replications. Differences in incidence of ear galls on plants inoculated at the early tassel or full-tassel stages or with inocula of sporidia or teliospores were not significant.

The "labor-saving" inoculation techniques (leaf sheath sprays and sandblasting) performed poorly at inducing formation of ear galls in these trials. The stalk inoculation technique increased incidence of ear galls; however, incidence was too low to be acceptable for commercial production of cuitlacoche or for evaluation of sweet corn hybrids for reactions to $U$. maydis. Conversely, incidence of galls on leaves, stalks, and tassels was extremely high following stalk injection, thus indicating that inoculation of plants with $U$. maydis increased infection. Additional research is needed to determine when and how to inoculate with $U$. maydis to consistently induce formation of ear galls that are necessary to commercially produce cuitlacoche and to screen for disease resistance. Recently, Pope and McCarter (1991) presented a preliminary report on a relatively successful technique in which sporidia were injected into cob tissue at the midsilk stage. Also, further research is needed to identify ways by which successful inoculation techniques can be made less labor intensive.

Other considerations. In addition to identifying susceptible corn genotypes and developing inoculation techniques that insure consistent formation of ear galls, several other factors should be considered before cuitla- 
coche can be produced commerically as an alternative crop. Some of these include: time and method of harvest, postharvest storage and handling, and build-up of inocula of $U$. maydis.

Yield and quality of cuitlacoche appear to be inversely related during the "harvest" period. Ear galls are relatively small and spongy and usually are protected by husk leaves until $\approx 8$ to 12 days after the midsilk stage (50\% of ears with silk). Galls continue to enlarge until 19 to 21 days after midsilk, when sweet corn is harvested for fresh market. Smut galls usually erupt through husk leaves $\approx 12$ to 18 days after midsilk. Sporulation of $U$. maydis also increases during this time, and most ear galls are too mature and are of unacceptable quality for cuitlacoche 19 days after midsilk. Also, species of Aspergillus, Fusarium, Mucor, Penicillium and other genera can colonize mature galls (Christensen, 1963), rendering them unacceptable and possibly even harmful if eaten.

Because ear galls are spongy and succulent, they are difficult to harvest and ship without damage. Likewise, smut galls deteriorate very rapidly in cold storage. Freezing appears to be a relatively easy method of maintaining gall integrity, but additional research on methods of harvest and postharvest handling and storage is necessary.

Finally, inoculation of plants to induce ear galls for a cash crop of cuitlacoche could be detrimental to subsequent crops of sweet corn. Ustilago maydis overwinters in the soil as teliospores. Although relationships between levels of initial inoculum and incidence of smut are not known, unharvested smut galls could potentially increase initial inoculum for subsequent crops of sweet corn planted in that field, or possibly, in adjacent fields. Therefore, cuitlacoche probably should not be grown as an alternative crop in fields that will be used for production of sweet corn, popcorn, or dent corn in subsequent years.

\section{Literature Cited}

Bojanowski, J. 1969. Studies of inheritance of reaction to common smut in corn. Theor. Applied Genet. 39:32-42.

Christensen, J.J. 1963. Corn smut caused by Ustilago maydis. Amer. Phytopathol. Soc. Monogr. 2.

Davis, G.N. 1936. Some of the factors influencing the infection and pathogenicity of Ustilago zeae (Beckm.) Unger on Zea mays L. Iowa Agr. Expt. Sta. Res. Bul. 199

Farm Journal. 1990. Cashing in on smut. Farm J. 114(6):29.

Kennedy, D. 1989. The art of Mexican cooking. Bantam, New York.

Nuberg, I.K., R.N. Allen, J.M. Colless, and R.E. Darnell. 1986. Field reactions of maize varieties commonly grown in Australia to boil smut caused by Ustilago zeae. Austral. J. Expt. Agr. 26:481-488.

Pataky, J.K. and J.M. Headrick. 1988. Illinois sweet corn disease nursery-1988, p. 100-107. In: J.E. Simon et al. (ed.) Midwest vegetable variety trial report for 1988. Purdue Univ. Agr. Expt. Sta. Bul. 551.

Pataky, J.K., J.M. Headrick. and Suparyono. 1987.
1987 sweet corn hybrid disease nursery, p. 1016. In: R.K. Lindstrom (ed.). Illinois vegetable research report. I11. Agr. Expt. Sta. Hort. Ser. 68.

Pataky, J.K., P. Fallah Moghaddam, and J.W. Gantz. 1990. Illinois sweet corn disease nursery-1990, p. 170-179. In: J.E. Simon et al. (ed.). Midwest vegetable variety trial report for 1990. Purdue Univ. Agr. Expt. Sta. Bul. 600.

Piemeisel, F.J. 1917. Factors affecting the parasitism of Usilago zeae. Phytopathology 7:294307

Pope, D.D. and S.M. McCarter. 1991. The effect of inoculation method on disease incidence and severity of the corn smut caused by Ustilago maydis Phytopathology 81:814.

Smith, D.R. and D.G. White. 1988. Diseases of corn, p. 687-766. In: G.F. Sprague and J.W. Dudley (eds.). Corn and corn improvement. 3rd ed. Amer. Soc. Agron., Madison, Wis.

Thakur, R.P., K.J. Leonard, and J.K. Pataky. 1989. Smut gall development in adult corn plants inoculated with Ustilago maydis Plant Dis. 73:921-925.

Walter, J.M. 1935. Factors affecting the development of corn smut, Ustilago zeae (Beckm.) Unger. Minn. Agr. Expt. Sta. Tech. Bul. 111.

Wilcoxson, R.D. 1975. The relationship between corn plant population and smut infections. Plant Dis. Rptr. 59:678-680. 